\title{
Phosphazene Base-Mediated Azide-Alkyne Click Polymerization toward 1,5-Regioregular Polytriazoles
}

\author{
Baixue Li,,$^{\dagger}$ Yong Liu,,$^{\dagger}$ Han Nie,,$^{\dagger}$ Anjun Qin ${ }^{*} \dagger$ and Ben Zhong Tang*, +
}

${ }^{\prime}$ State Key Laboratory of Luminescent Materials and Devices, Center for Aggregation-Induced Emission, South China University of Technology, Guangzhou 510640, China.

Department of Chemistry, Hong Kong Branch of Chinese National Engineering Research Center for Tissue Restoration and Reconstruction, Institute for Advanced Study, and Department of Chemical and Biological Engineering, The Hong Kong University of Science \& Technology, Clear Water Bay, Kowloon, Hong Kong, China. 


\section{Table of Contents}

Synthesis procedures of monomers $\mathbf{1 a}$ and $\mathbf{1 b}$.

Synthesis procedures of monomers $\mathbf{2 a - 2 c}$.

Figure S1. TGA curves of PI-PVI. $T_{\text {d }}$ presents the temperature of $5 \%$ weight loss.

Figure S2. FT-IR spectra of 1a (A), 2 b (B) and PII (C).

Figure S3. FT-IR spectra of 1a (A), 2c (B) and PIII (C).

Figure S4. FT-IR spectra of 1b (A), 2a (B) and PIV (C).

Figure S5. FT-IR spectra of 1b (A), 2b (B) and PV (C).

Figure S6. FT-IR spectra of $\mathbf{1 b}(\mathrm{A}), \mathbf{2 c}(\mathrm{B})$ and PVI (C).

Figure S7. ${ }^{1} \mathrm{H}$ NMR spectra of $\mathbf{2 b}(\mathrm{A})$, 1a (B) and PII (C) in DMSO- $d_{6}$. The solvent peaks are marked with asterisks.

Figure S8. ${ }^{1} \mathrm{H}$ NMR spectra of $2 \mathrm{c}(\mathrm{A})$, 1a (B) and PIII (C) in DMSO- $d 6$. The solvent peaks are marked with asterisks.

Figure S9. ${ }^{1} \mathrm{H}$ NMR spectra of 2a (A), 1b (B) and PIV (C) in DMSO-d6. The solvent peaks are marked with asterisks.

Figure S10. ${ }^{1} \mathrm{H}$ NMR spectra of $\mathbf{2 b}(\mathrm{A}), \mathbf{1 b}(\mathrm{B})$ and PV (C) in DMSO- $d_{6}$. The solvent peaks are marked with asterisks.

Figure S11. ${ }^{1} \mathrm{H}$ NMR spectra of 2c (A), 1b (B) and PVI (C) in DMSO- $d 6$. The solvent peaks are marked with asterisks.

Figure S12. ${ }^{13} \mathrm{C}$ NMR spectra of 2a (A), 1a (B) and PI (C) in DMSO-d6. The solvent peaks are marked with asterisks.

Figure S13. ${ }^{13} \mathrm{C}$ NMR spectra of $\mathbf{2 b}(\mathrm{A}), \mathbf{1 a}(\mathrm{B})$ and PII (C) in DMSO- $d_{6}$. The solvent peaks are 
marked with asterisks.

Figure S14. ${ }^{13} \mathrm{C}$ NMR spectra of $2 \mathrm{c}(\mathrm{A})$, 1a (B) and PIII (C) in DMSO- $d_{6}$. The solvent peaks are marked with asterisks.

Figure S15. ${ }^{13} \mathrm{C}$ NMR spectra of $2 \mathbf{a}(\mathrm{A}), \mathbf{1 b}(\mathrm{B})$ and PIV (C) in DMSO- $d 6$. The solvent peaks are marked with asterisks.

Figure S16. ${ }^{13} \mathrm{C}$ NMR spectra of $\mathbf{2 b}(\mathrm{A}), \mathbf{1 b}(\mathrm{B})$ and PV (C) in DMSO- $d 6$. The solvent peaks are marked with asterisks.

Figure S17. ${ }^{13} \mathrm{C}$ NMR spectra of $2 \mathbf{c}(\mathrm{A}), \mathbf{1 b}(\mathrm{B})$ and PVI (C) in DMSO- $d_{6}$. The solvent peaks are marked with asterisks. S20

Figure S18. FT-IR spectra of 1b (A), 2c (B) and PVI' (C). S2 1

Figure S19. ${ }^{1} \mathrm{H}$ NMR spectra of 2c (A), 1b (B) and PVI' (C) in DMSO-d6. The solvent peaks are marked with asterisks.

Figure S20. ${ }^{13} \mathrm{C}$ NMR spectra of $\mathbf{2 c}(\mathrm{A}), \mathbf{1 b}(\mathrm{B})$ and PVI' (C) in DMSO- $d_{6}$. The solvent peaks are marked with asterisks.

Figure S21. FT-IR spectra of 1b (A), 2c (B) and PVII (C).

Figure S22. ${ }^{1} \mathrm{H}$ NMR spectra of $2 \mathbf{c}(\mathrm{A}), \mathbf{1 b}(\mathrm{B})$ and PVII (C) in $\mathrm{CDCl}_{3}$. The solvent peaks are marked with asterisks. S25

Figure S23. ${ }^{13} \mathrm{C}$ NMR spectra of 2c (A), $1 \mathbf{b}(\mathrm{B})$ and PVII (C) in $\mathrm{CDCl}_{3}$. The solvent peaks are marked with asterisks.

Figure S24. TGA (A) and DSC (B) curves of PVI' and PVII at a heating rate of (A) $20{ }^{\circ} \mathrm{C} / \mathrm{min}$ and (B) $10{ }^{\circ} \mathrm{C} / \mathrm{min}$ under nitrogen. S26

Figure S25. Light refraction spectra of thin solid films of PVI' and PVII. S27 
Figure S26. UV-vis absorption spectra of PVI' and PVII in THF solutions (A), PL spectra PVI' (B) and PVII (C) in THF solutions.

Figure S27. Dihedral angles of PVI'-M and PVII-M.

Figure S28. Cyclic voltammograms of PVI' and PVII with an $\mathrm{Hg} / \mathrm{HgCl}_{2}$ electrode as the reference electrode and an energy level of ferrocene of $-4.40 \mathrm{eV}$ as the internal standard. $\quad$ S28

Table S1. Photophysical and Calculated Results as well as thermal property of PVI' and PVII. S28

\section{References}




\section{Synthesis procedures of monomers $1 \mathrm{a}$ and $1 \mathrm{~b}$.}

\section{Synthesis of 4,4'-diazidobiphenyl (1a)}

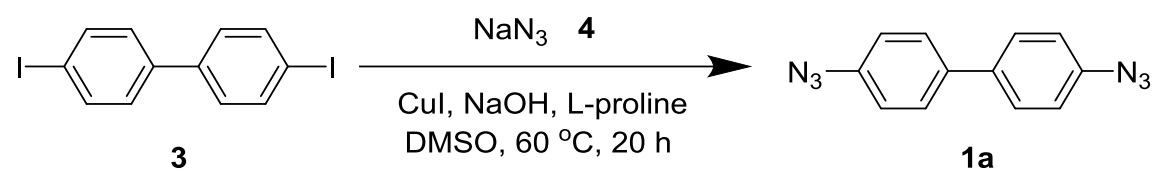

This monomer was prepared according to our previously published procedures. ${ }^{1}$

Synthesis of 1,6-bis(4-azidophenoxy)hexane (1b)

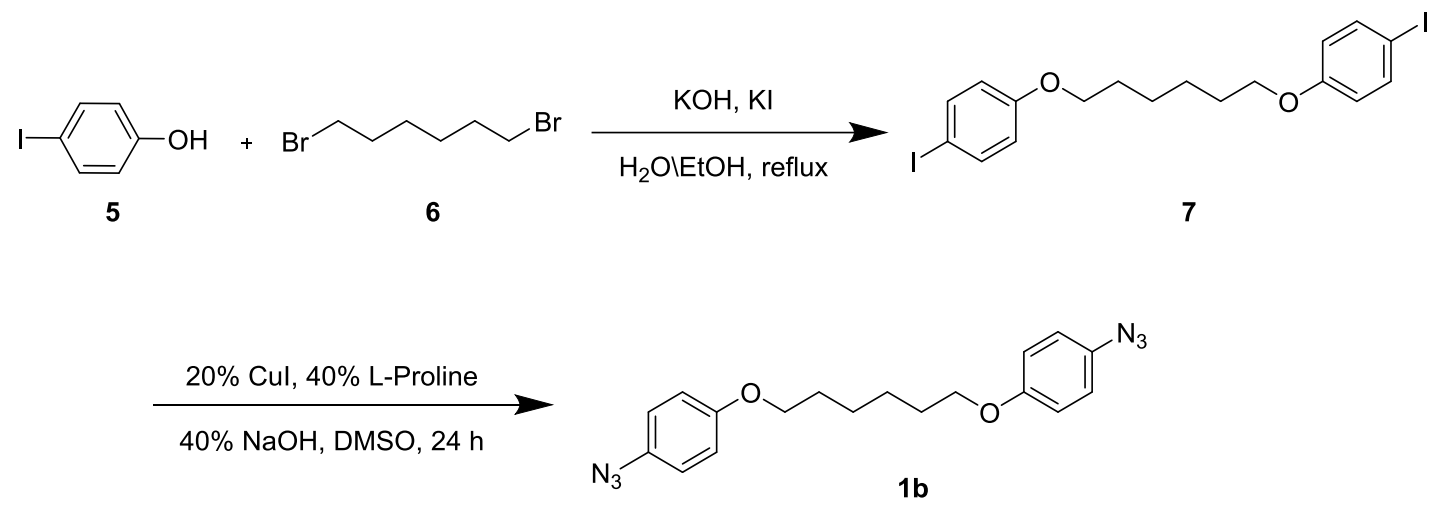

This monomer was prepared according to our previously published procedures. ${ }^{2}$

\section{Synthesis procedures of monomers $2 \mathrm{a}-2 \mathrm{c}$.}

Synthesis of $4,4^{\prime}$-(Isopropylidenediphenyl)-bis(4-ethynylbenzyl) ether (2a)

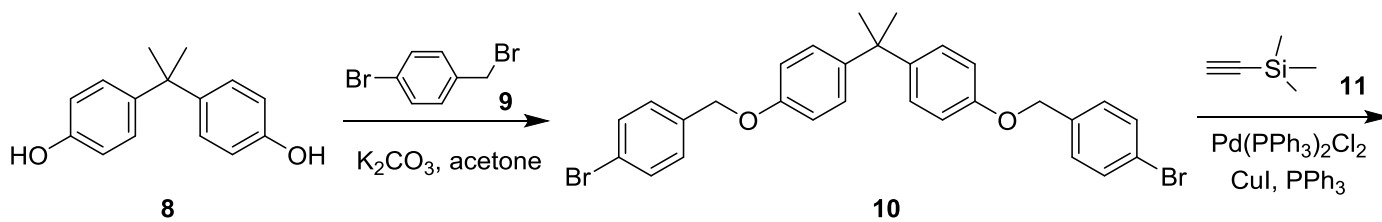

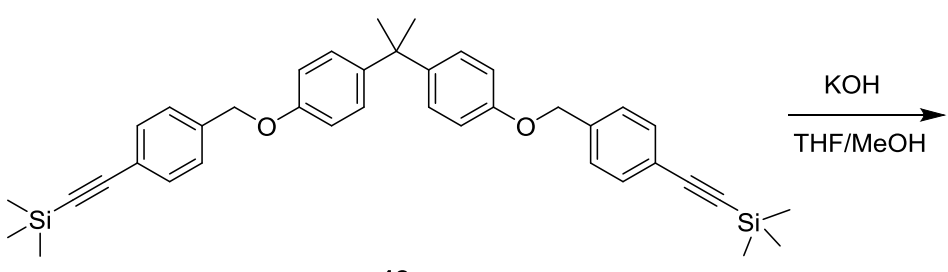

12<smiles>C#Cc1ccc(COc2ccc(C(C)(C)c3ccc(OCc4ccc(C#C)cc4)cc3)cc2)cc1</smiles>

$\mathbf{2 a}$

This monomer was prepared according to our previously published procedures. ${ }^{3,4}$ 


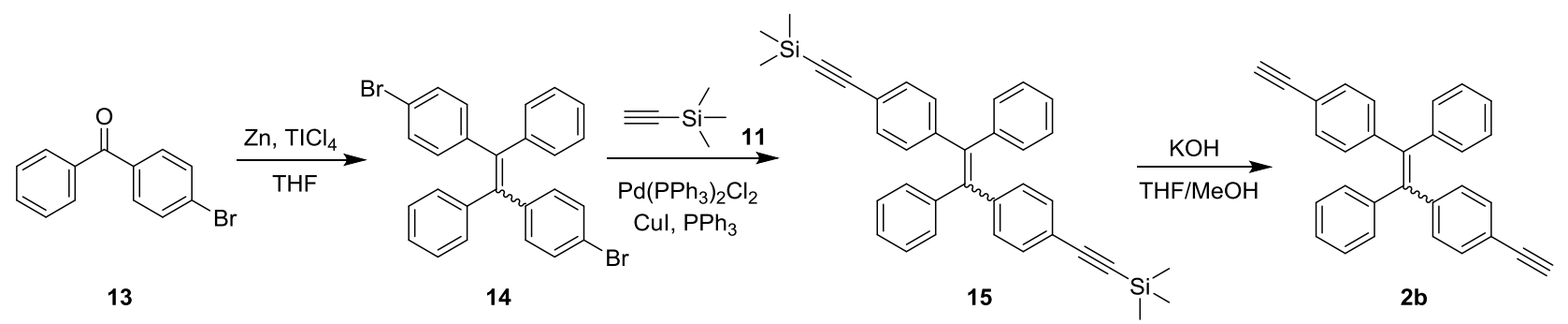

This monomer was prepared according to our previously published procedures. ${ }^{3,4}$

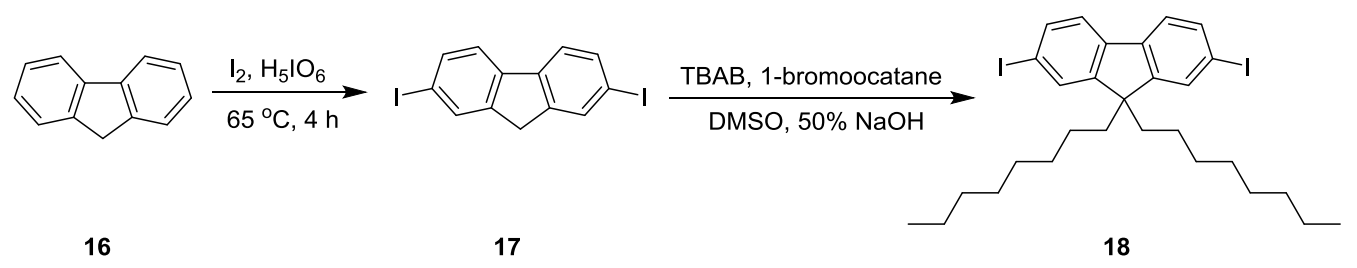

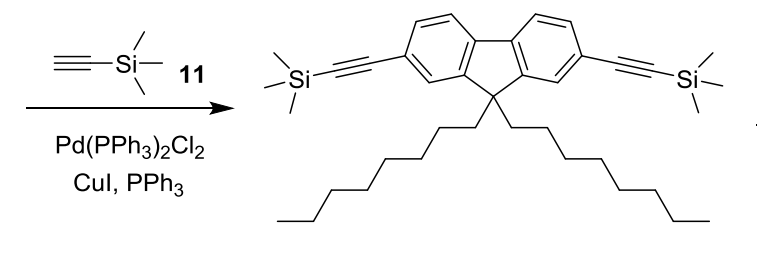

19

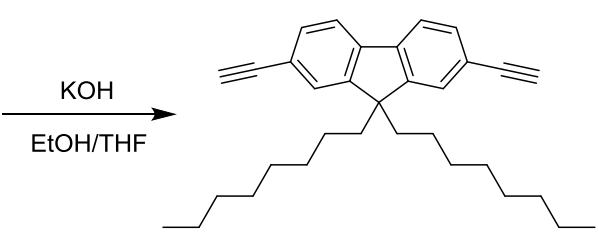

2c

This monomer was prepared according to our previously published procedures. ${ }^{5}$

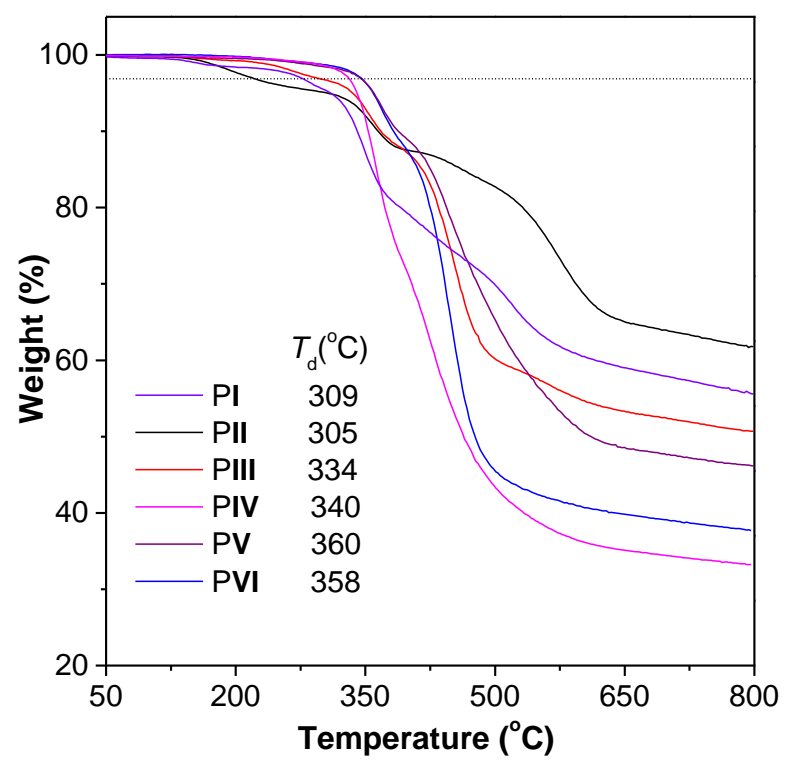

Figure S1. TGA curves of PI-PVI. $T_{\mathrm{d}}$ presents the temperature of 5\% weight loss. 


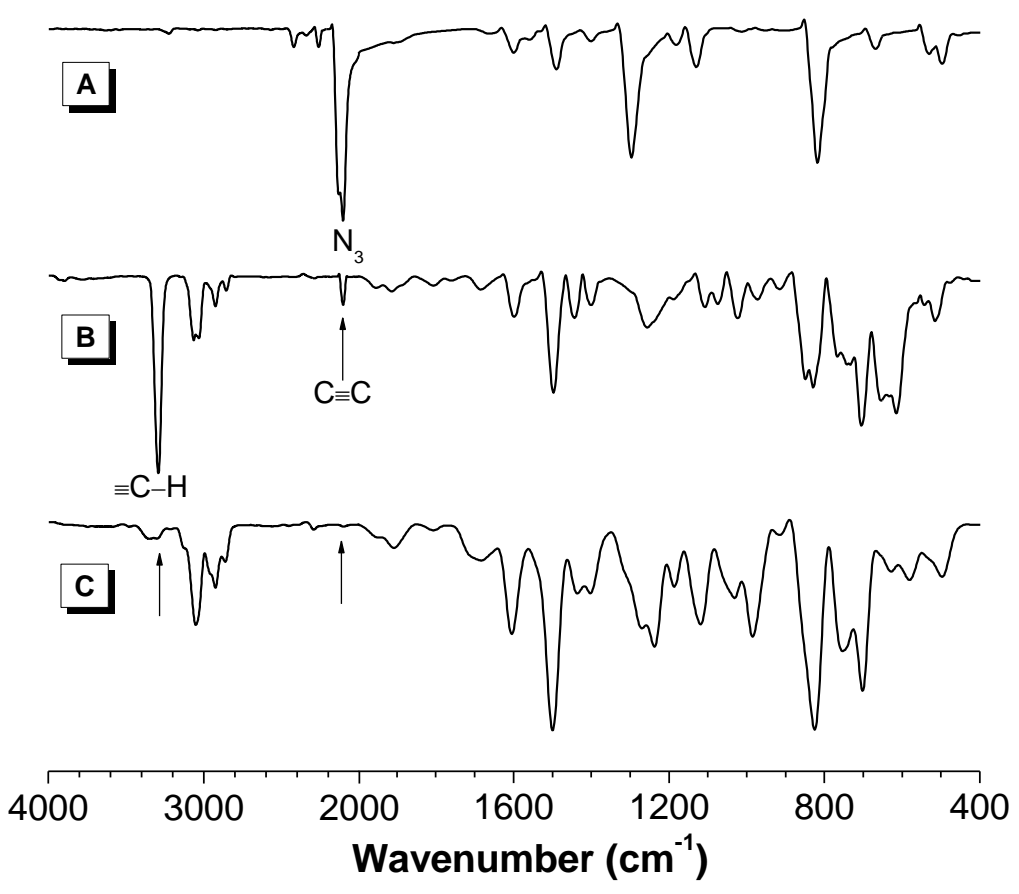

Figure S2. FT-IR spectra of 1a (A), 2b (B) and PII (C).

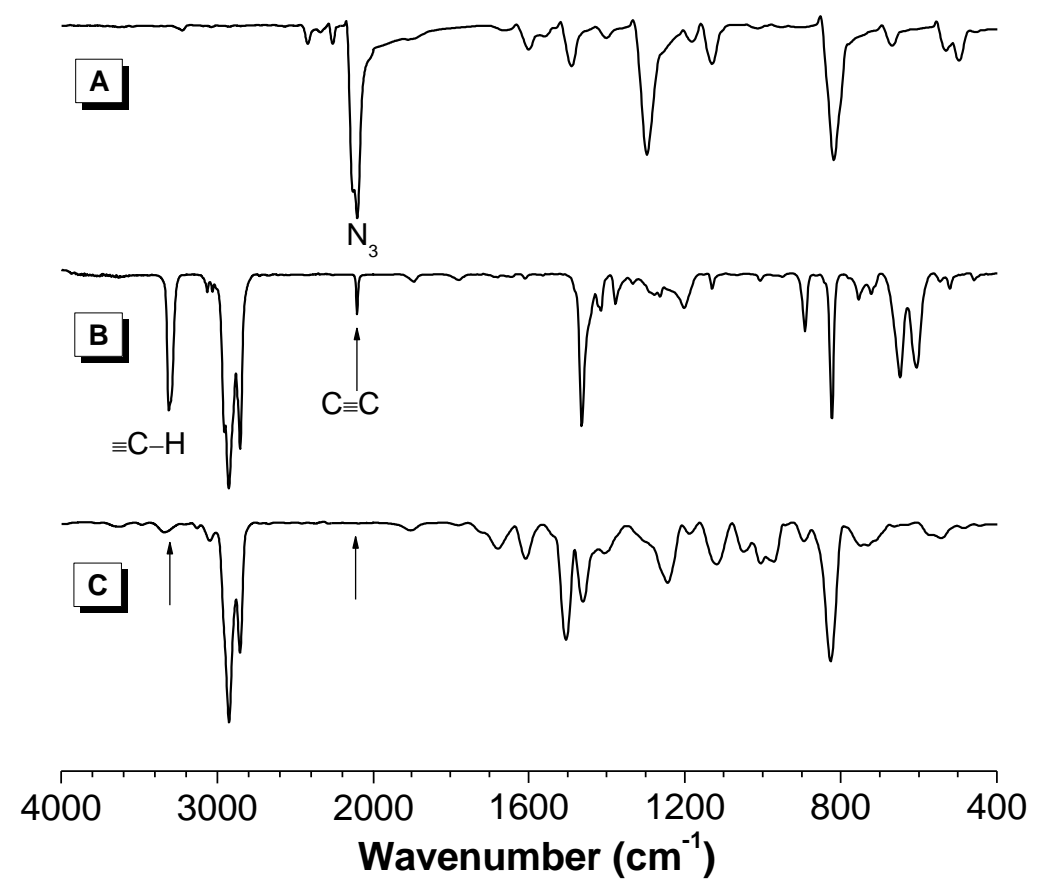

Figure S3. FT-IR spectra of 1a (A), 2c (B) and PIII (C). 


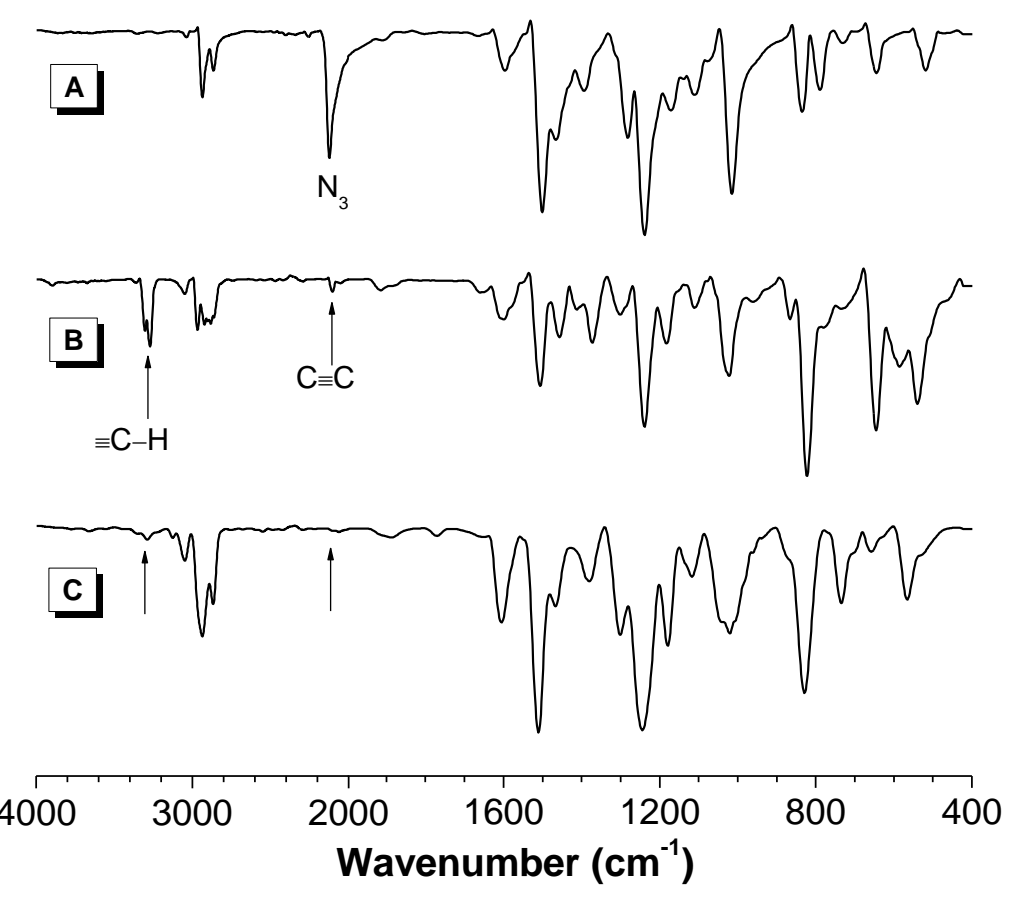

Figure S4. FT-IR spectra of $\mathbf{1 b}(\mathrm{A}), \mathbf{2 a}(\mathrm{B})$ and PIV (C).

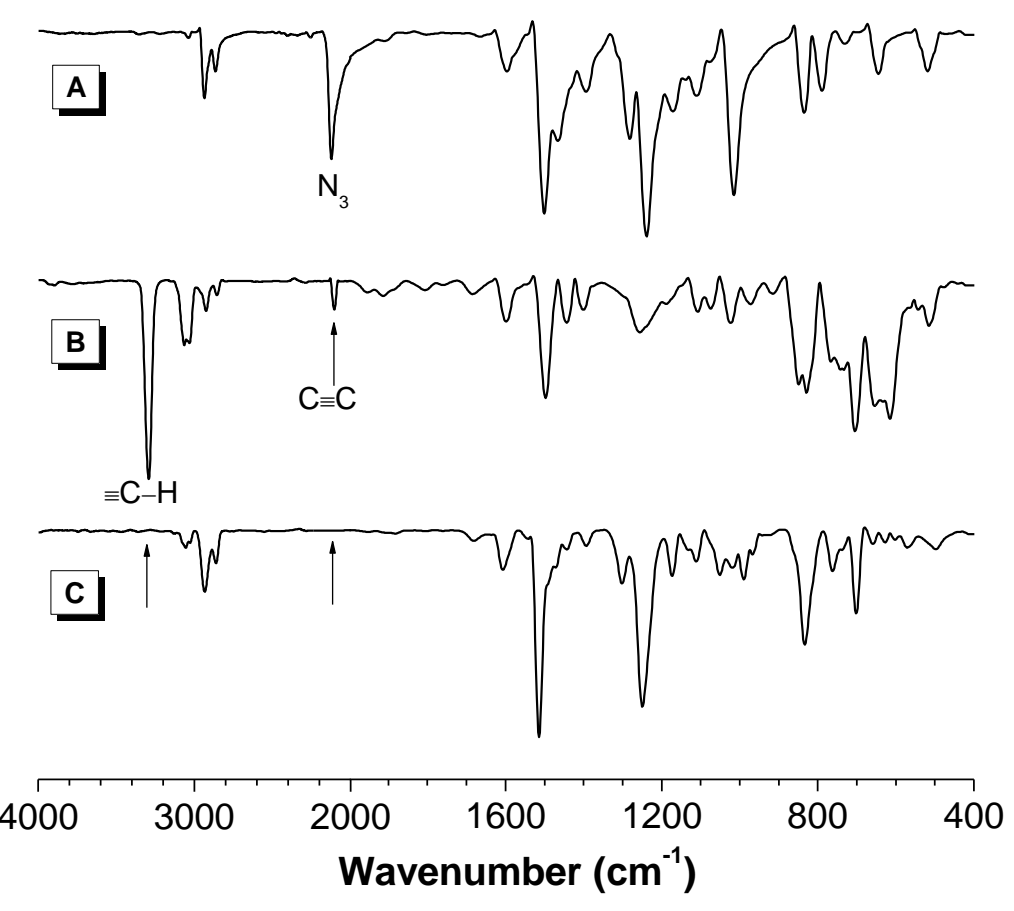

Figure S5. FT-IR spectra of $\mathbf{1 b}(\mathrm{A}), \mathbf{2 b}(\mathrm{B})$ and PV (C). 


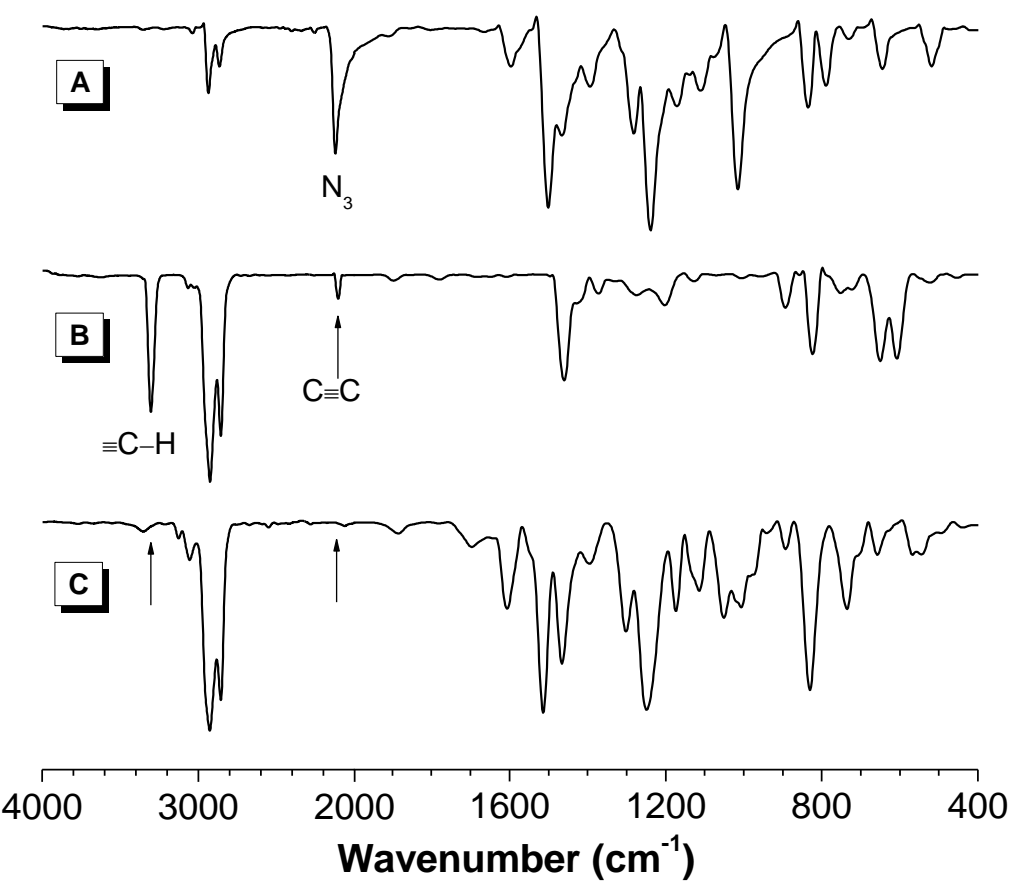

Figure S6. FT-IR spectra of $\mathbf{1 b}(\mathrm{A}), \mathbf{2 c}(\mathrm{B})$ and PVI (C). 

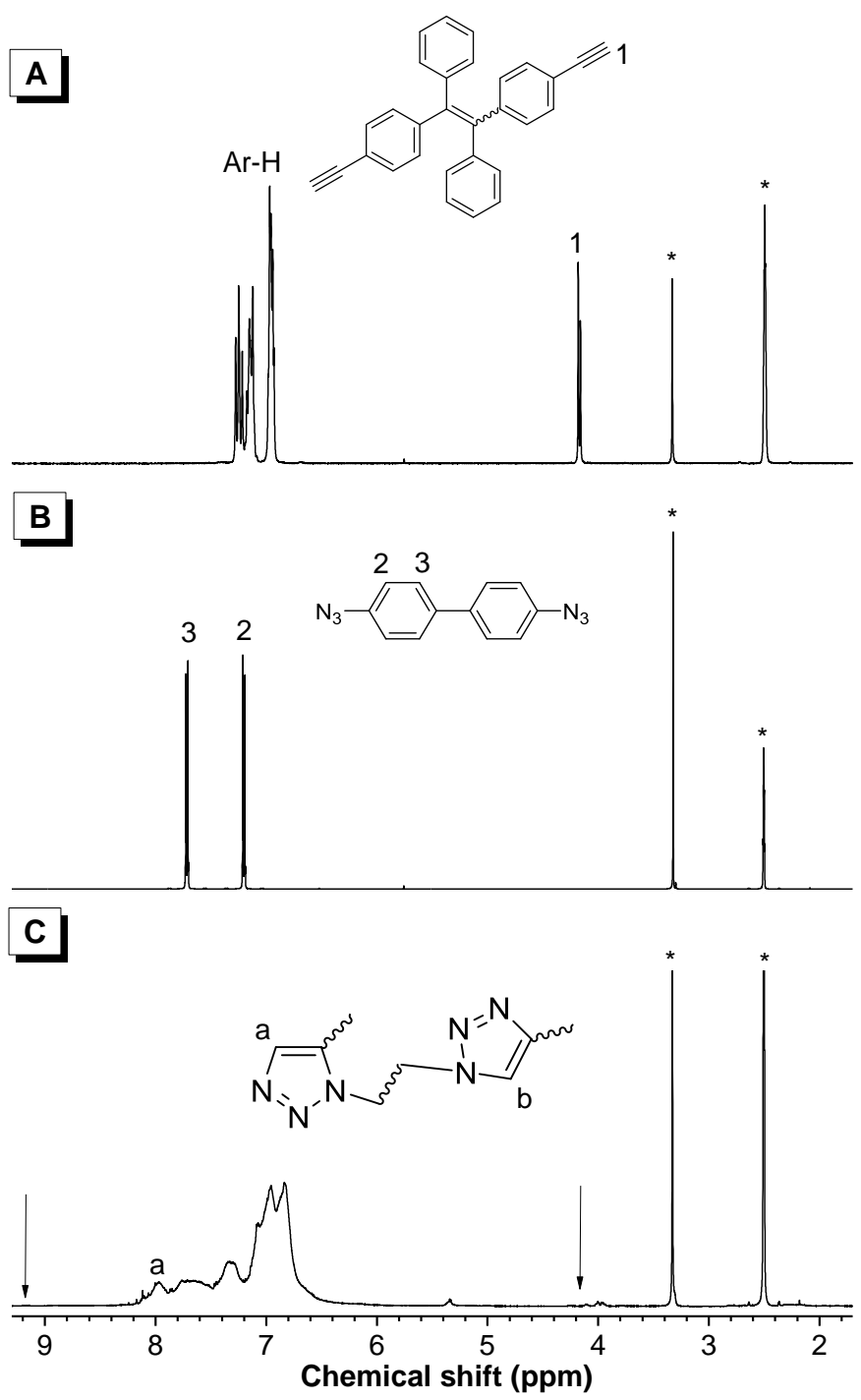

Figure S7. ${ }^{1} \mathrm{H}$ NMR spectra of $\mathbf{2 b}(\mathrm{A}), \mathbf{1 a}(\mathrm{B})$ and PII (C) in DMSO- $d_{6}$. The solvent peaks are marked with asterisks. 

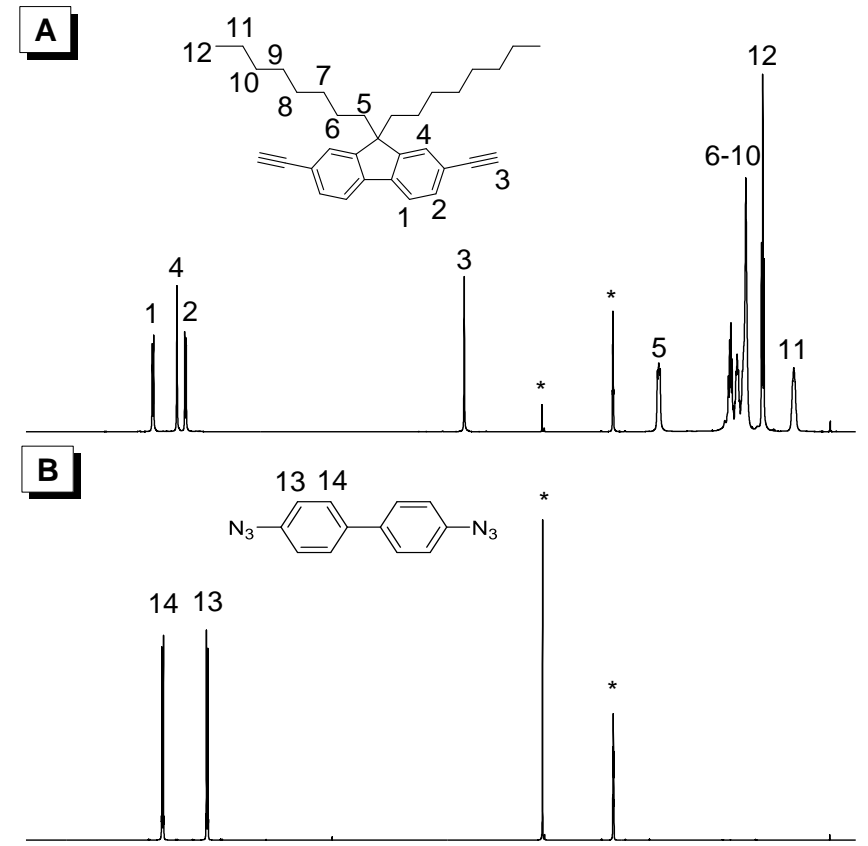

c]

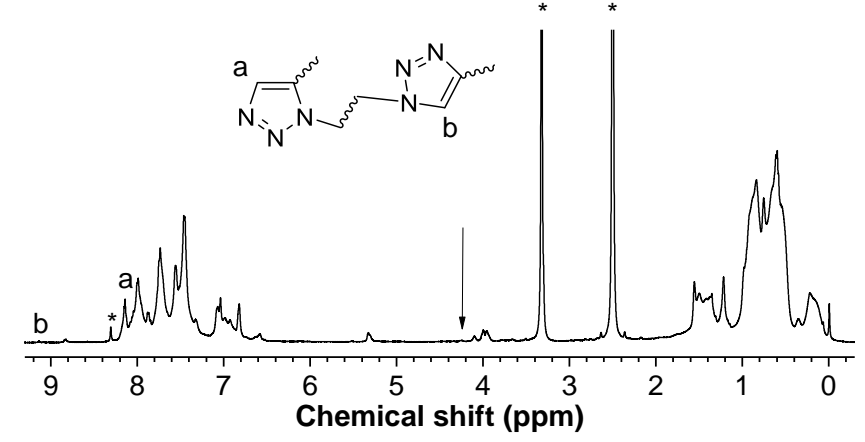

Figure S8. ${ }^{1} \mathrm{H}$ NMR spectra of $2 \mathrm{c}(\mathrm{A})$, 1a (B) and PIII (C) in DMSO-d6. The solvent peaks are marked with asterisks. 

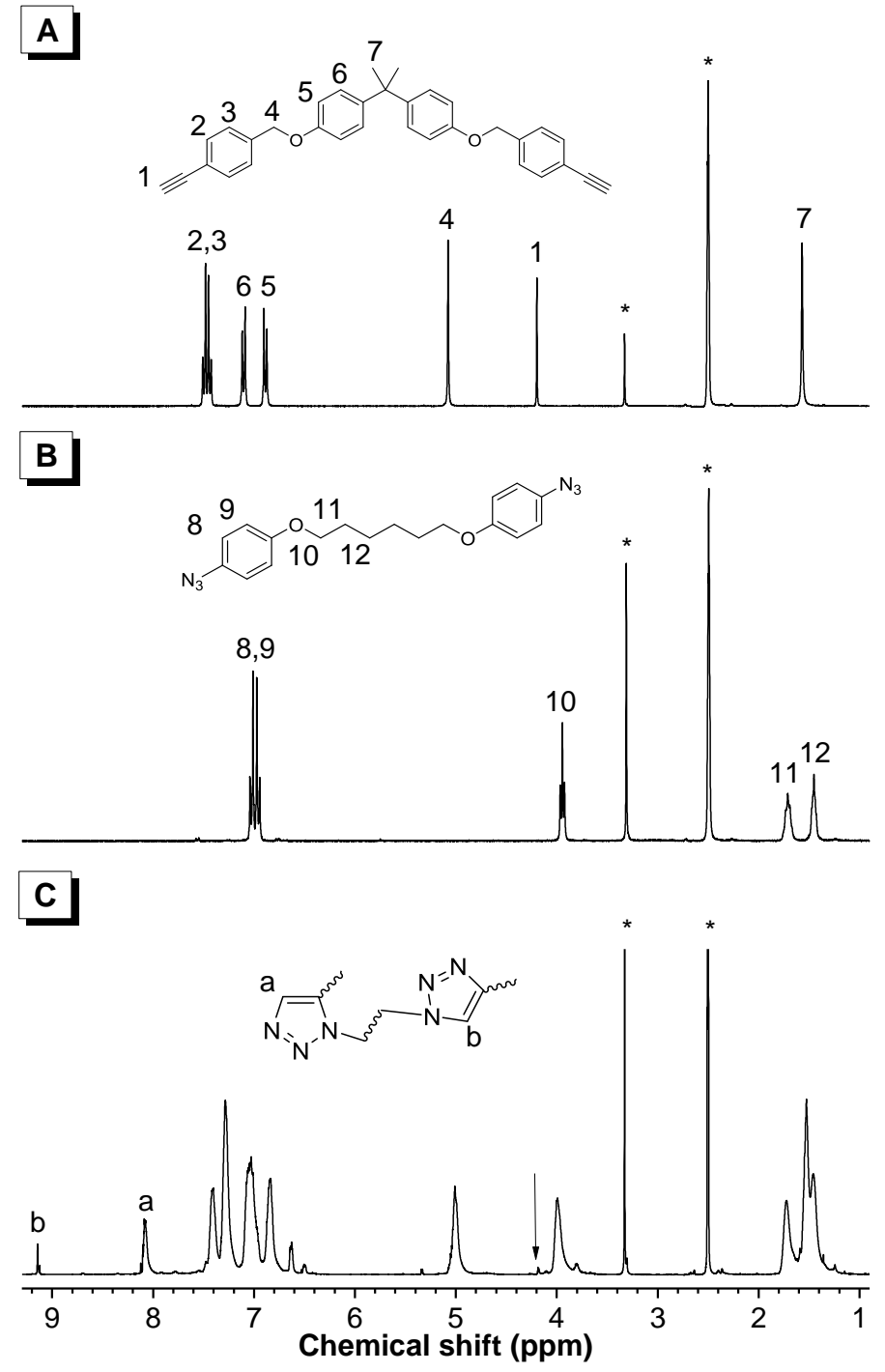

Figure S9. ${ }^{1} \mathrm{H}$ NMR spectra of 2a (A), 1b (B) and PIV (C) in DMSO-d6. The solvent peaks are marked with asterisks. 

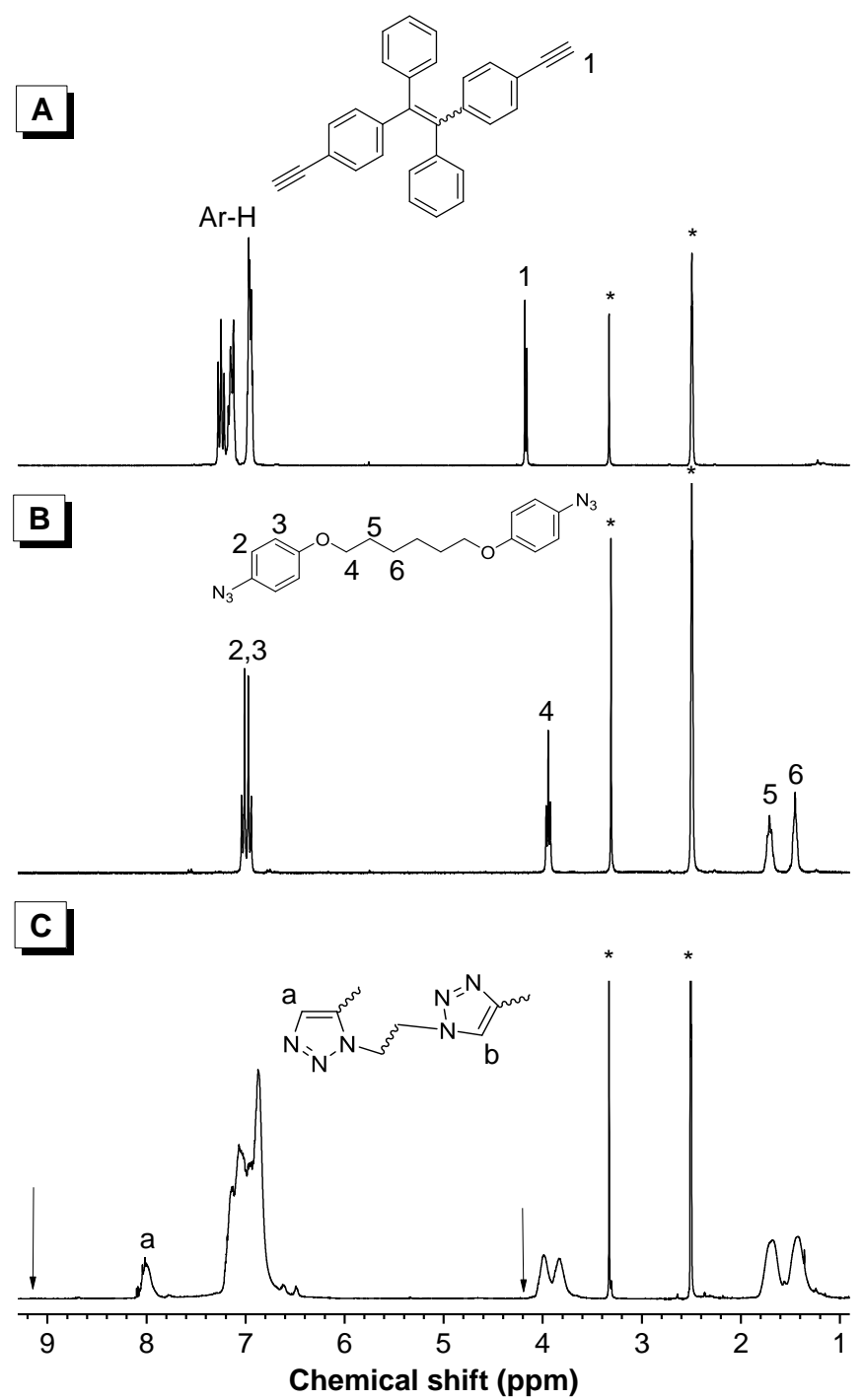

Figure S10. ${ }^{1} \mathrm{H}$ NMR spectra of $\mathbf{2 b}(\mathrm{A}), \mathbf{1 b}(\mathrm{B})$ and PV (C) in DMSO-d6. The solvent peaks are marked with asterisks. 

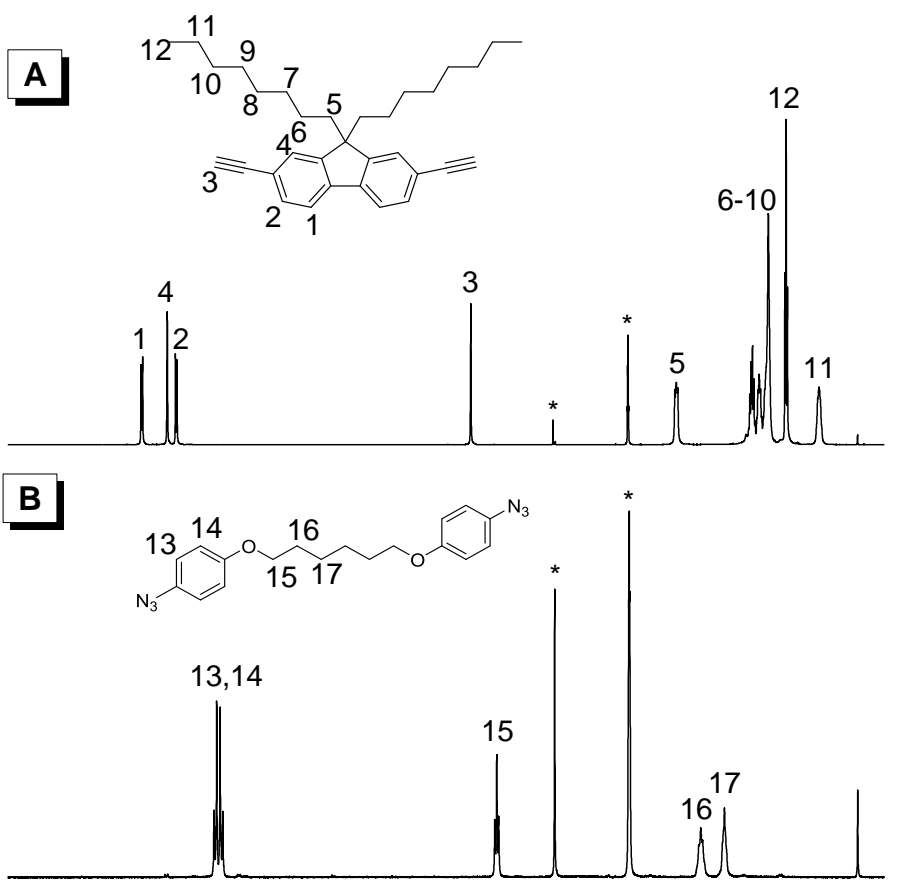

c]

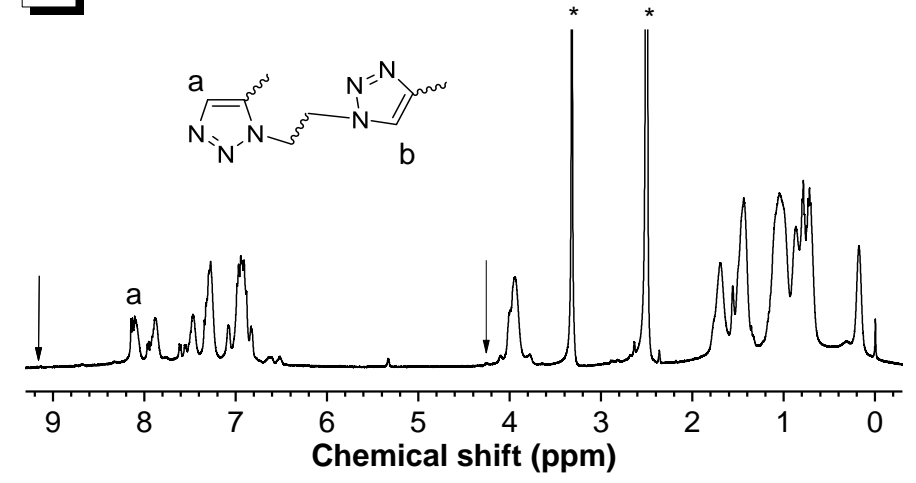

Figure S11. ${ }^{1} \mathrm{H}$ NMR spectra of $2 \mathbf{c}(\mathrm{A}), \mathbf{1 b}(\mathrm{B})$ and PVI (C) in DMSO- $d_{6}$. The solvent peaks are marked with asterisks. 

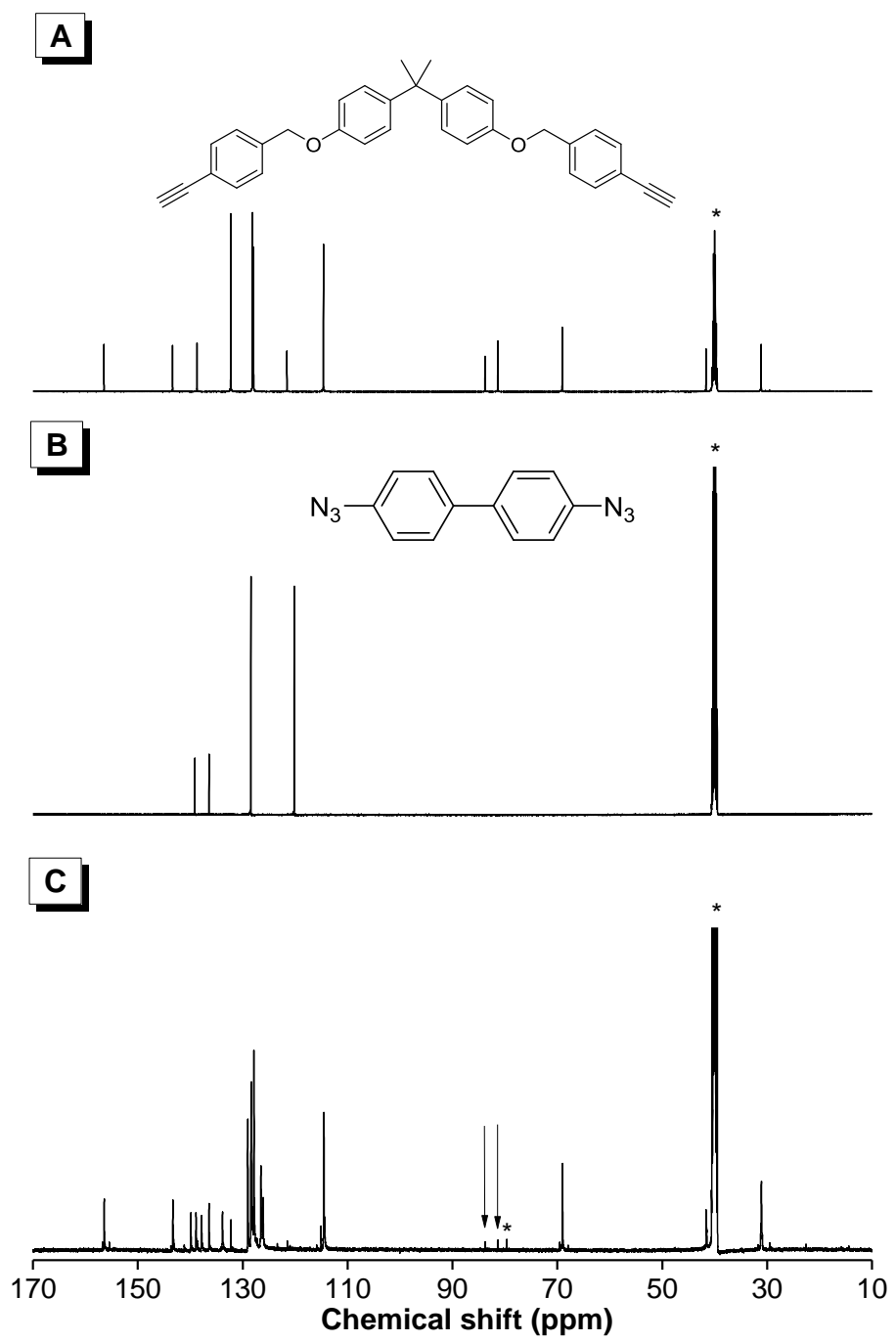

Figure S12. ${ }^{13} \mathrm{C}$ NMR spectra of 2a (A), 1a (B) and PI (C) in DMSO- $d_{6}$. The solvent peaks are marked with asterisks. 

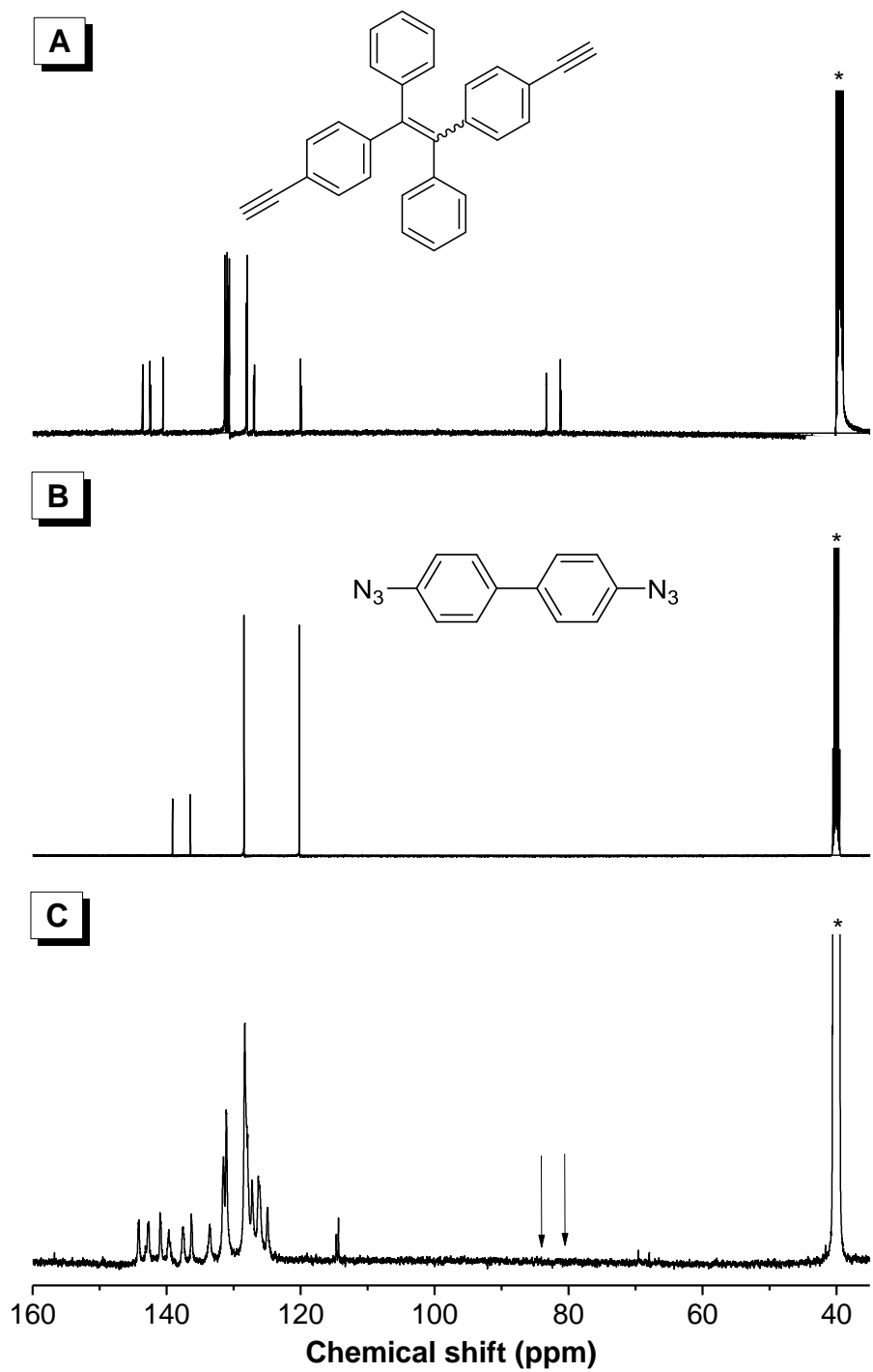

Figure S13. ${ }^{13} \mathrm{C}$ NMR spectra of $\mathbf{2 b}(\mathrm{A}), \mathbf{1 a}(\mathrm{B})$ and PII (C) in DMSO- $d_{6}$. The solvent peaks are marked with asterisks. 

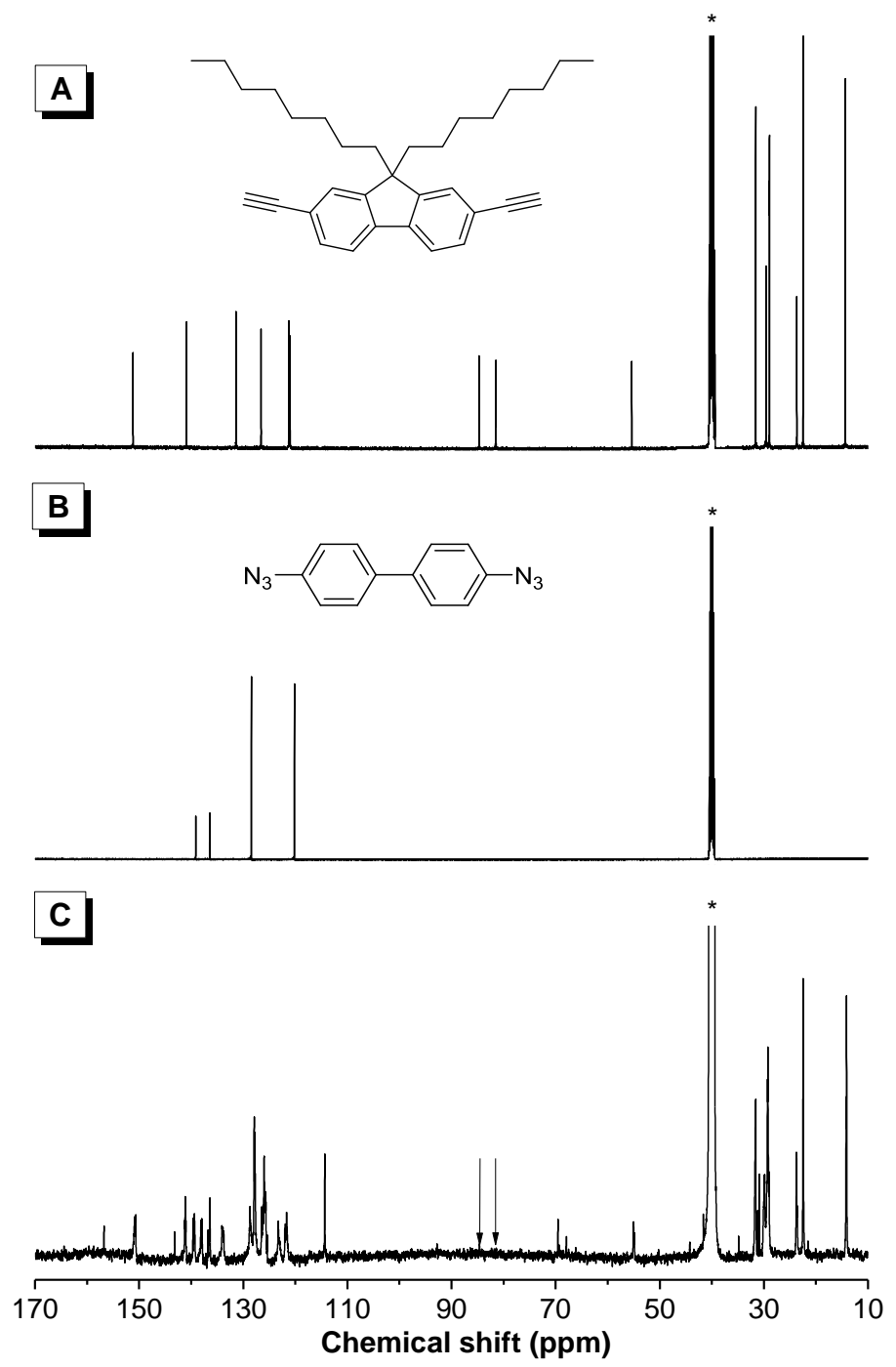

Figure S14. ${ }^{13} \mathrm{C}$ NMR spectra of 2c (A), 1a (B) and PIII (C) in DMSO-d6. The solvent peaks are marked with asterisks. 


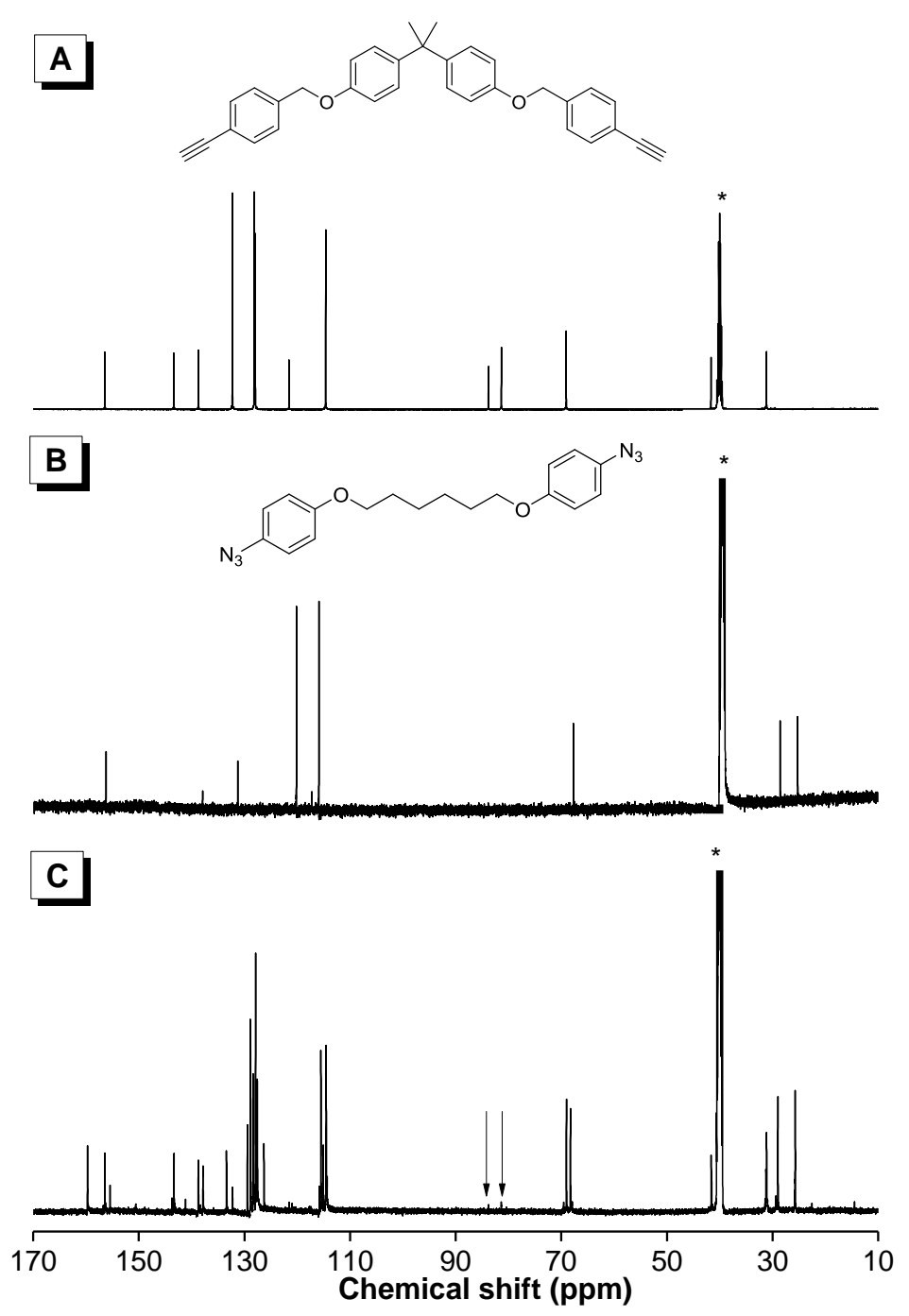

Figure S15. ${ }^{13} \mathrm{C}$ NMR spectra of 2a (A), 1b (B) and PIV (C) in DMSO- $d 6$. The solvent peaks are marked with asterisks. 


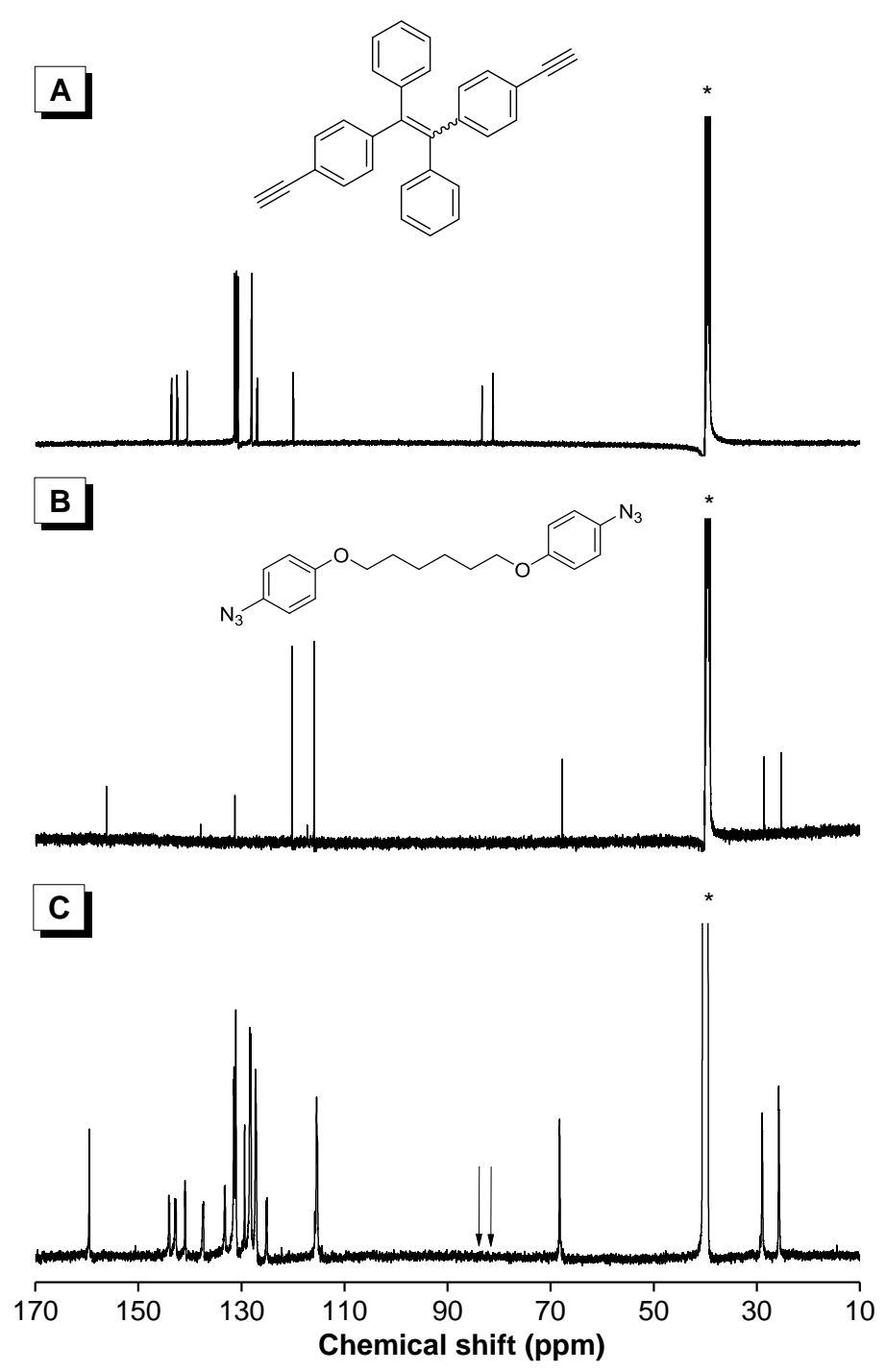

Figure S16. ${ }^{13} \mathrm{C}$ NMR spectra of $\mathbf{2 b}(\mathrm{A}), \mathbf{1 b}(\mathrm{B})$ and PV (C) in DMSO- $d_{6}$. The solvent peaks are marked with asterisks. 


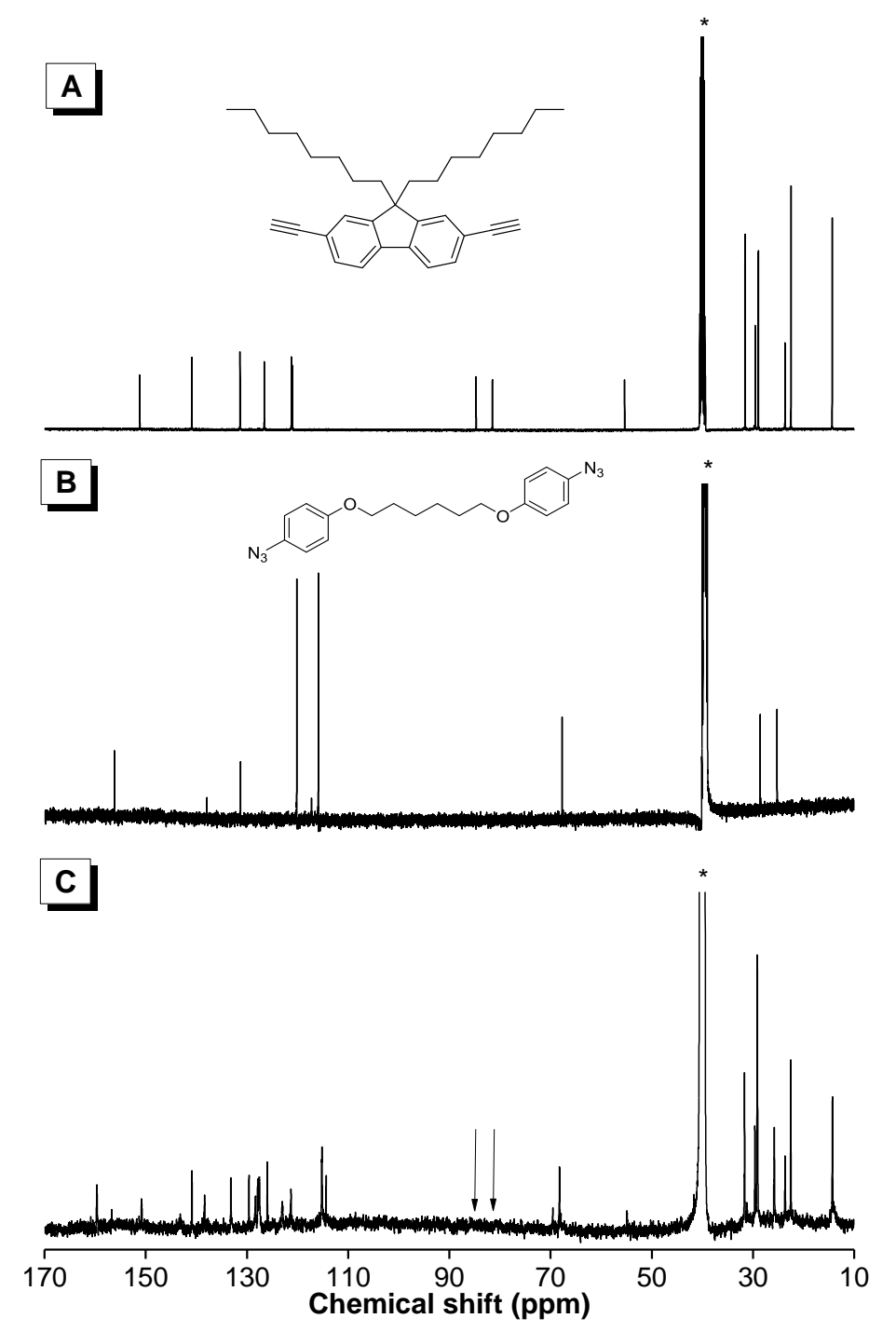

Figure S17. ${ }^{13} \mathrm{C}$ NMR spectra of $2 \mathbf{c}(\mathrm{A}), \mathbf{1 b}(\mathrm{B})$ and PVI (C) in DMSO-d6. The solvent peaks are marked with asterisks. 


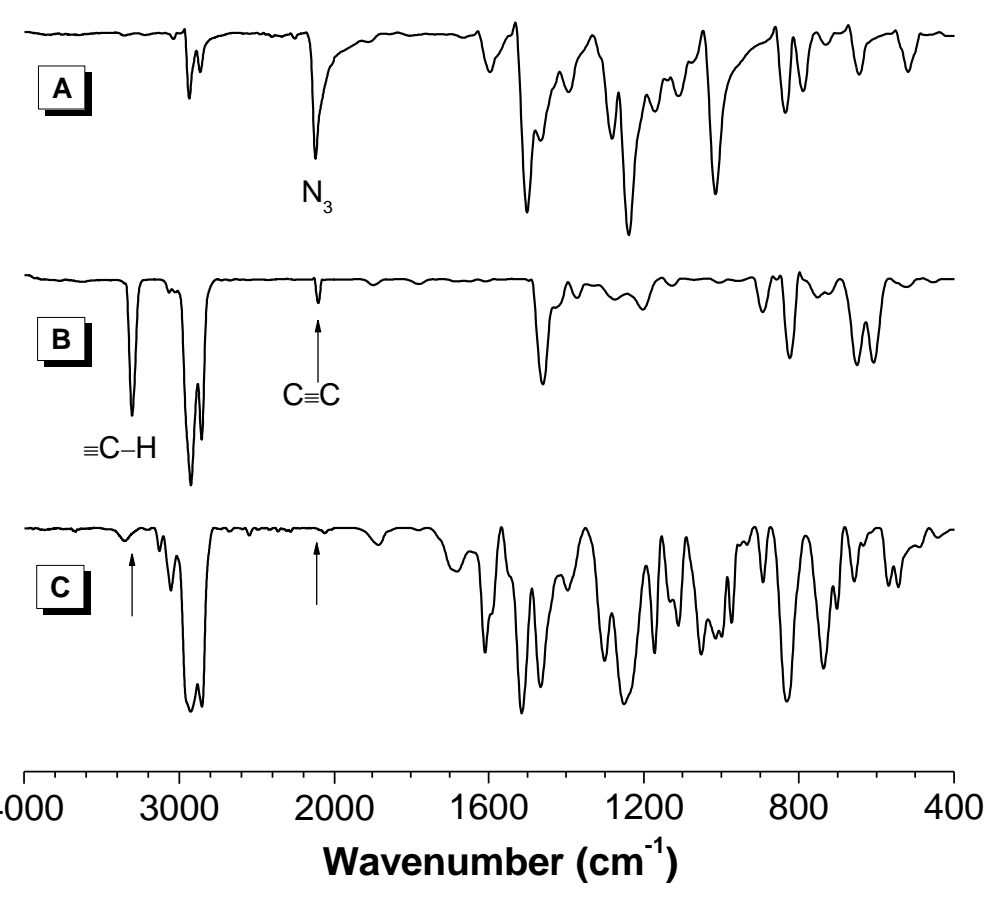

Figure S18. FT-IR spectra of 1b (A), 2c (B) and PVI' (C). 



Figure S19. ${ }^{1} \mathrm{H}$ NMR spectra of 2c (A), 1b (B) and PVI' (C) in DMSO-d6. The solvent peaks are marked with asterisks. 


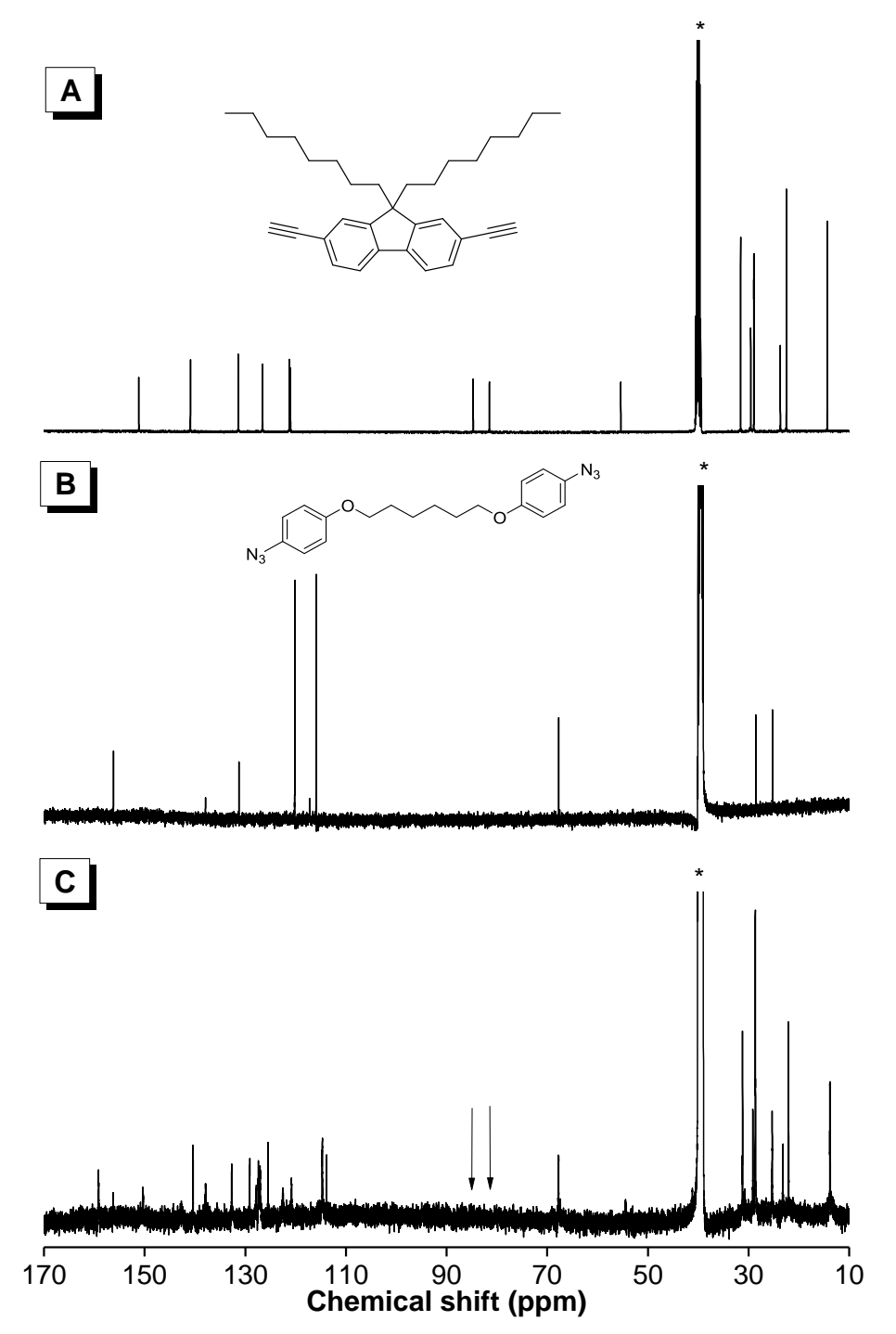

Figure S20. ${ }^{13} \mathrm{C}$ NMR spectra of 2c (A), 1b (B) and PVI' (C) in DMSO- $d 6$. The solvent peaks are marked with asterisks. 


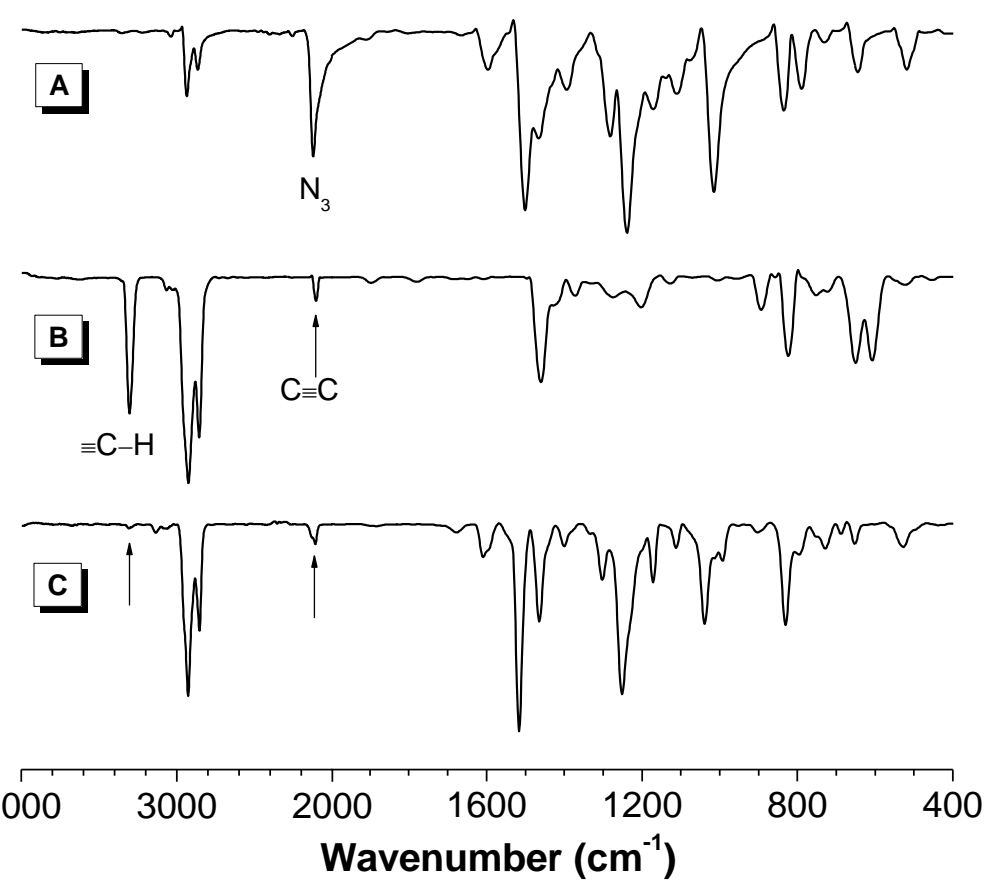

Figure S21. FT-IR spectra of 1b (A), 2c (B) and PVII (C). 

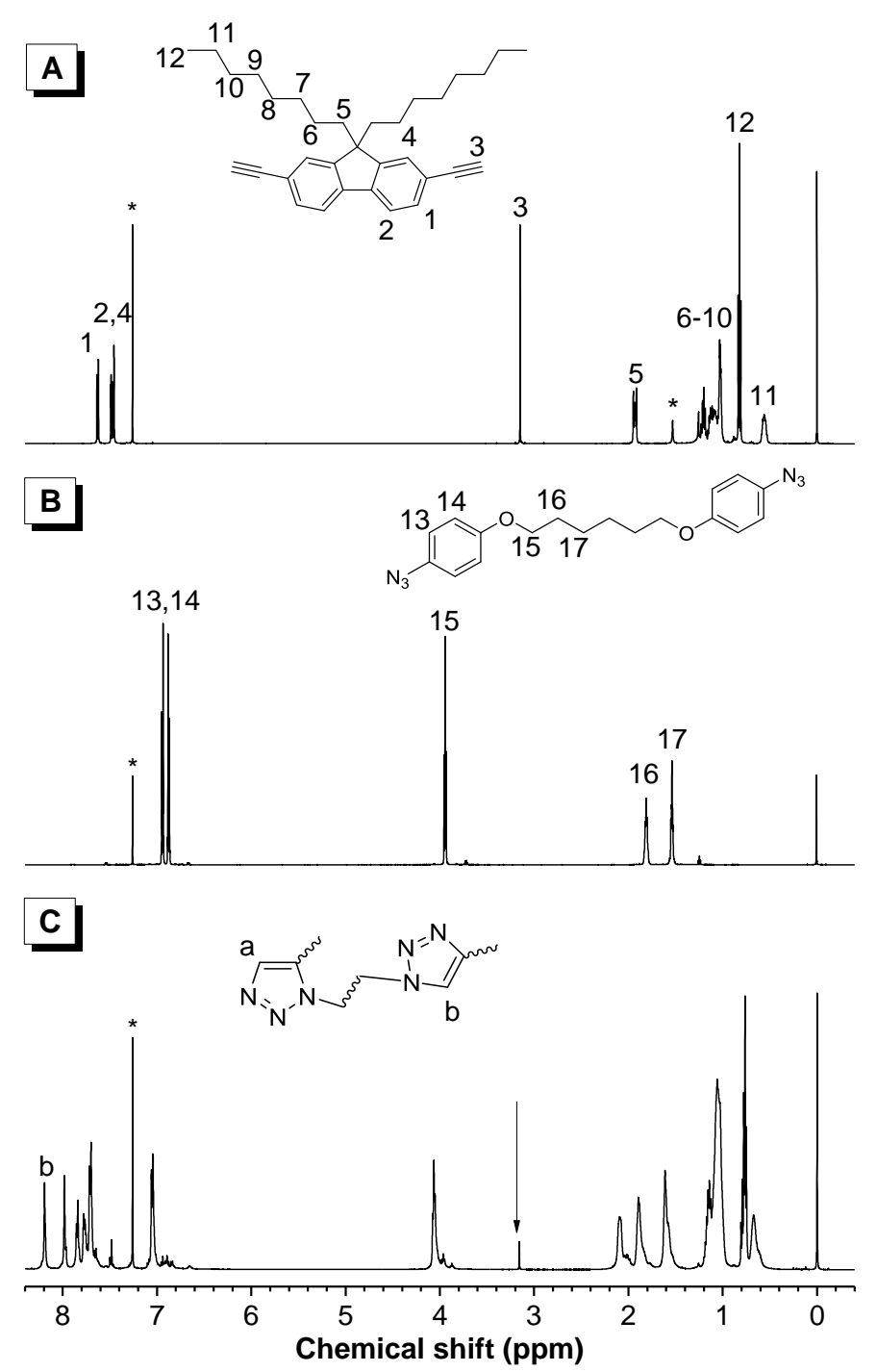

Figure S22. ${ }^{1} \mathrm{H}$ NMR spectra of $2 \mathbf{c}(\mathrm{A}), \mathbf{1 b}(\mathrm{B})$ and PVII (C) in $\mathrm{CDCl}_{3}$. The solvent peaks are marked with asterisks. 


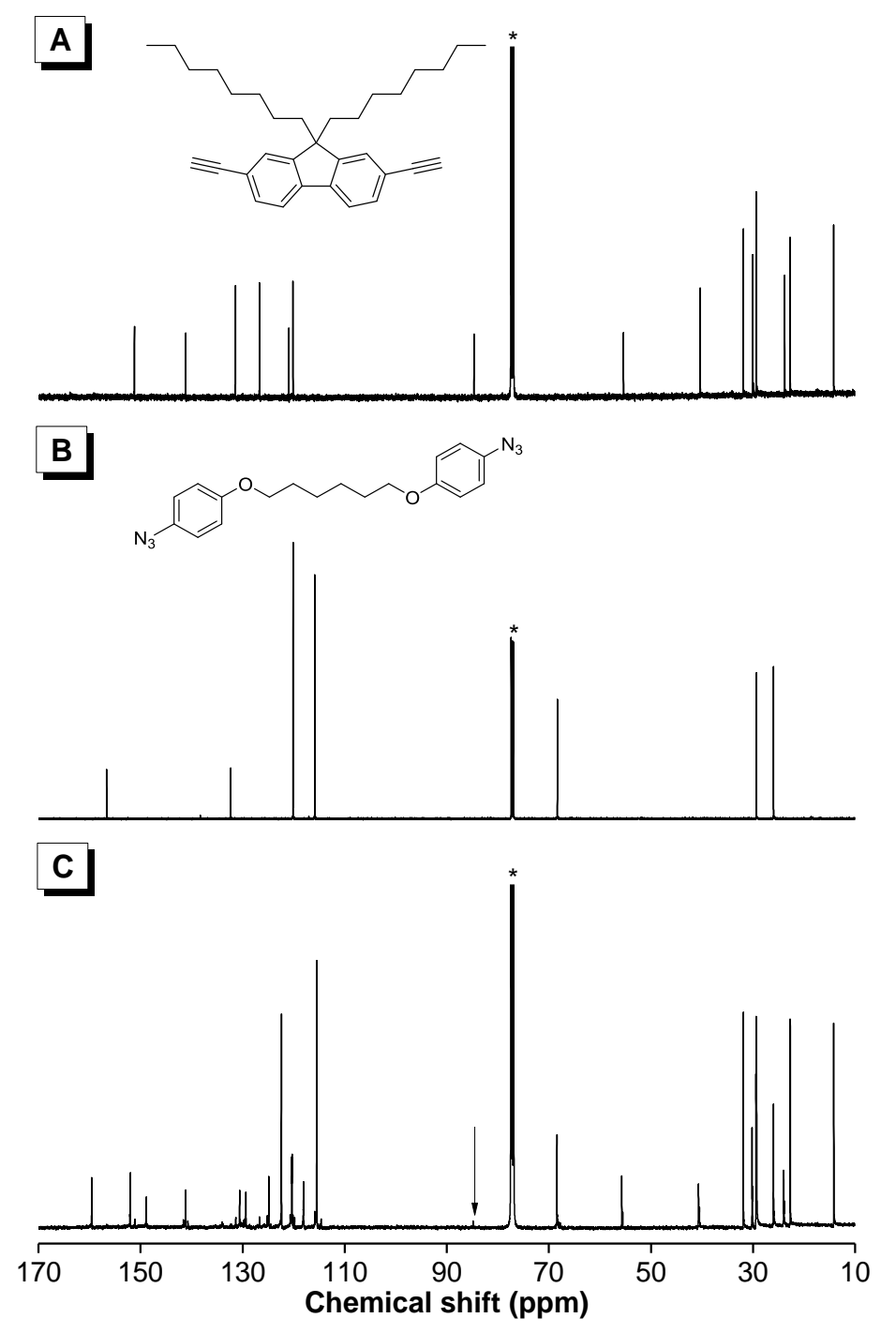

Figure S23. ${ }^{13} \mathrm{C}$ NMR spectra of $2 \mathbf{c}(\mathrm{A}), \mathbf{1 b}(\mathrm{B})$ and PVII (C) in $\mathrm{CDCl}_{3}$. The solvent peaks are marked with asterisks.
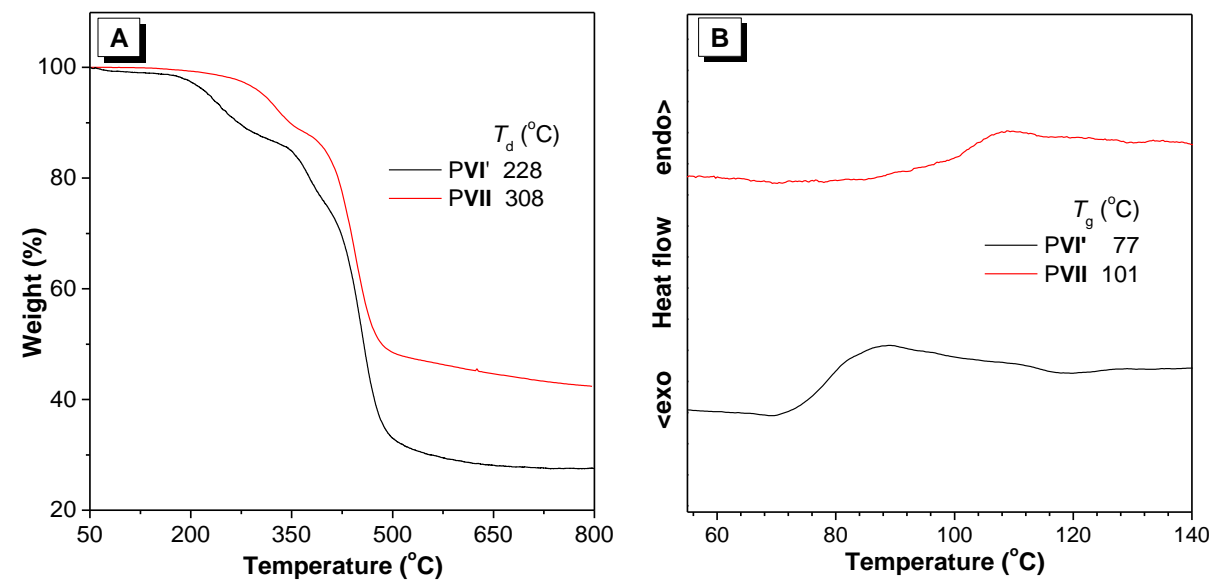

Figure S24. TGA (A) and DSC (B) curves of PVI' and PVII at a heating rate of (A) $20^{\circ} \mathrm{C} / \mathrm{min}$ and (B) $10^{\circ} \mathrm{C} / \mathrm{min}$ under nitrogen. 


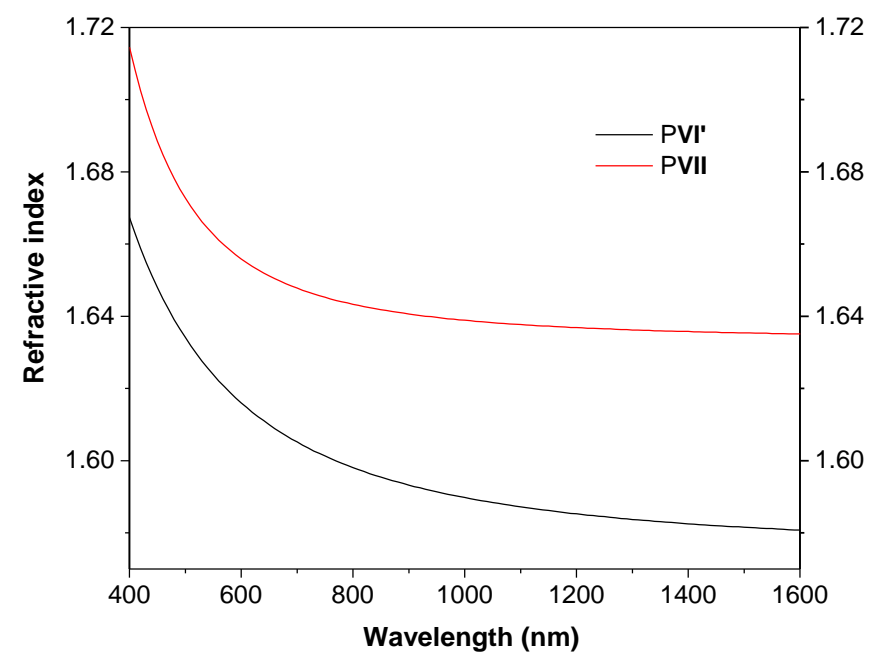

Figure S25. Light refraction spectra of thin solid films of PVI' and PVII.
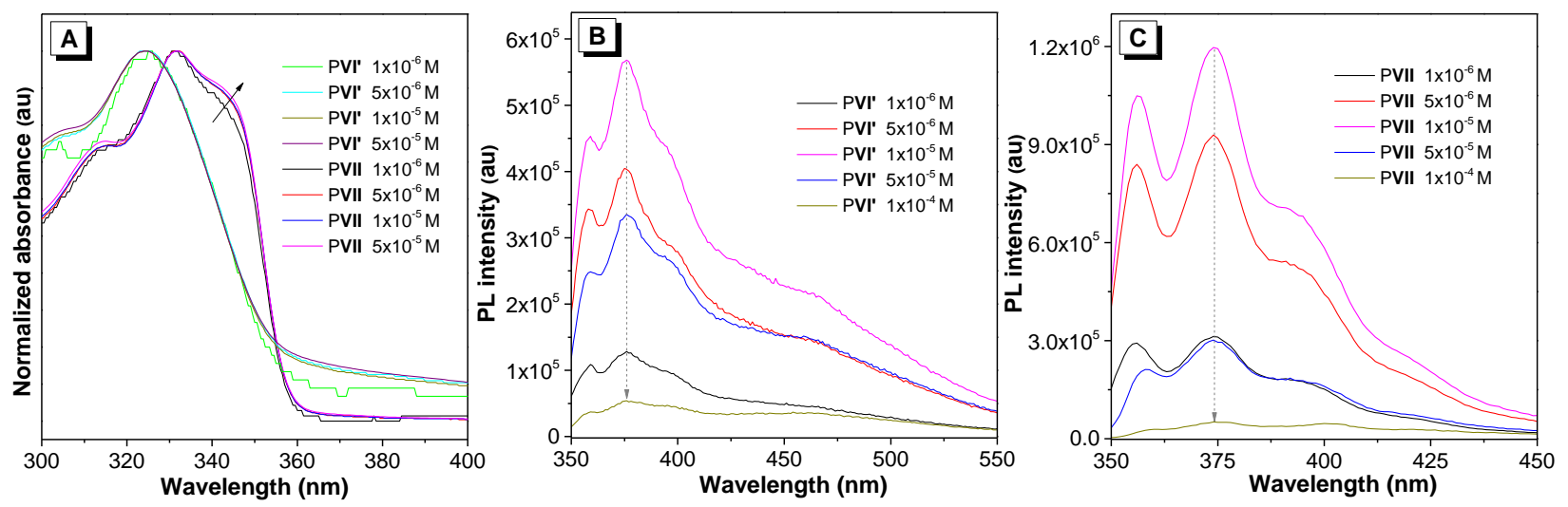

Figure S26. UV-vis absorption spectra of PVI' and PVII in THF solutions (A), PL spectra PVI' (B) and PVII (C) in THF solutions.
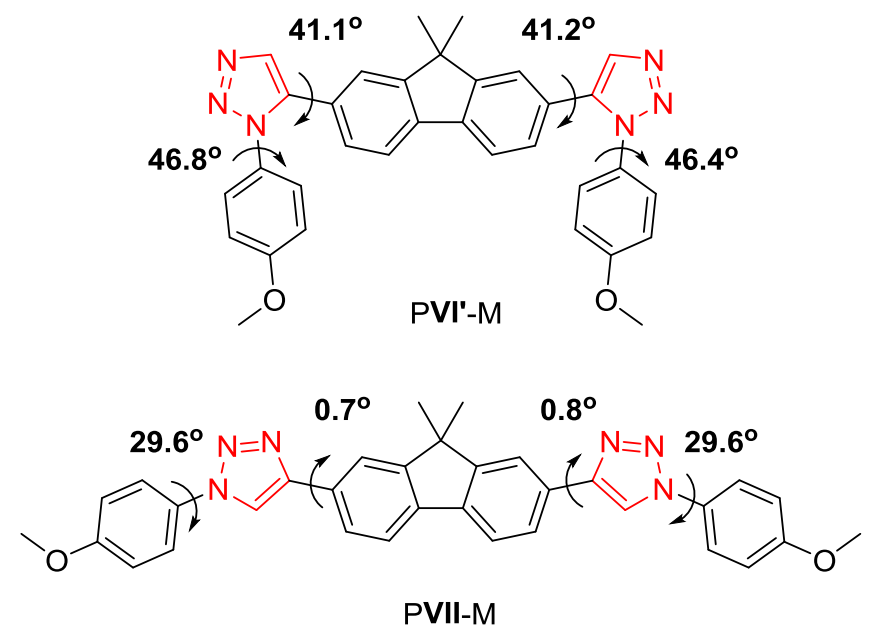

Figure S27. Dihedral angles of PVI'-M and PVII-M. 


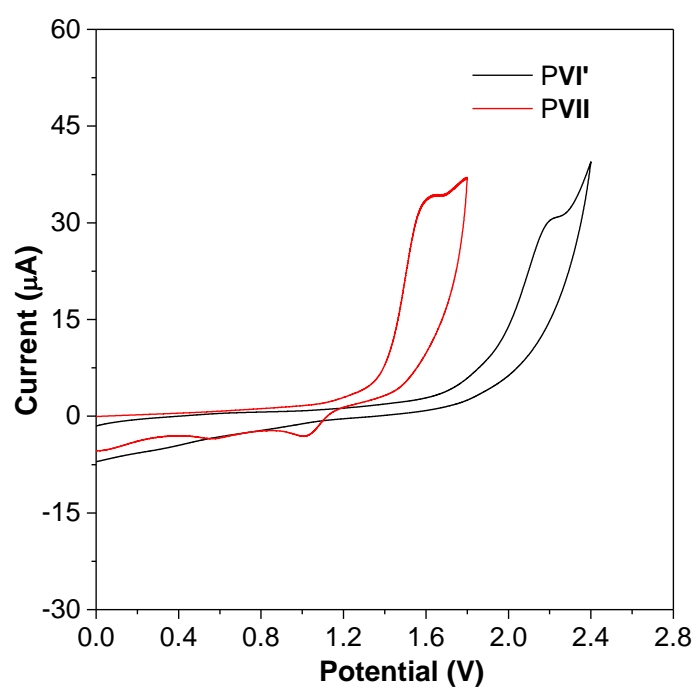

Figure S28. Cyclic voltammograms of PVI' and PVII with an $\mathrm{Hg} / \mathrm{HgCl}_{2}$ electrode as the reference electrode and an energy level of ferrocene of $-4.40 \mathrm{eV}$ as the internal standard.

Table S1. Photophysical and Calculated Results as well as Thermal Property of PVI' and PVII

\begin{tabular}{cccccccc}
\hline entry & $M_{\mathrm{w}}{ }^{a}$ & $\Xi^{a}$ & $\begin{array}{c}\lambda_{\mathrm{abs}}{ }^{b} \\
(\mathrm{~nm})\end{array}$ & $\begin{array}{c}\Phi_{\mathrm{F}}{ }^{c} \\
(\%)\end{array}$ & $\begin{array}{c}\tau \\
(\mathrm{ns})\end{array}$ & $\begin{array}{c}E_{\mathrm{g}}{ }^{d} \\
(\mathrm{eV})\end{array}$ & $\begin{array}{c}T_{\mathrm{g}} / T_{\mathrm{d}} \\
\left({ }^{\circ} \mathrm{C}\right)\end{array}$ \\
\hline PVI' & 13800 & 1.95 & 324 & 12.6 & 1.48 & 3.52 & $77 / 228$ \\
PVII & 10500 & 1.29 & 332 & 41.6 & 1.30 & 3.47 & $101 / 308$
\end{tabular}

${ }^{a}$ Estimated by APC using THF as an eluant on the basis of a PS calibration; $M_{\mathrm{w}}=$ weight-average molecular weight; polydispersity index $(\bigoplus)=M_{\mathrm{w}} / M_{\mathrm{n}} ; M_{\mathrm{n}}=$ number-average molecular weight. ${ }^{b} \mathrm{In}$ THF solutions $\left(10^{-5} \mathrm{M}\right) .{ }^{c}$ Absolute fluorescence quantum yield in THF solutions $\left(10^{-5} \mathrm{M}\right) .{ }^{d}$ Estimated by optical band gap calculated from the onset of absorption spectra.

\section{References}

(1) Yuan, W.; Mahtab, F.; Gong, Y.; Yu, Z.; Lu, P.; Tang, Y.; Lam, J. W. Y.; Zhu, C.; Tang, B. Z. Synthesis and Self-Assembly of Tetraphenylethene and Biphenyl Based AIE-Active Triazoles. $J$. Mater. Chem. 2012, 22, 10472-10479.

(2) Liu, Y.; Wang, J.; Huang, D.; Zhang, J.; Guo, S.; Hu, R.; Zhao, Z.; Qin, A.; Tang, B. Z. Synthesis of 1,5-Regioregular Polytriazoles by Efficient $\mathrm{NMe}_{4} \mathrm{OH}-\mathrm{Mediated}$ Azide-Alkyne Click Polymerization. Polym. Chem. 2015, 6, 5545-5549.

(3) Wang, J.; Mei, J.; Yuan, W.; Lu, P.; Qin, A.; Sun, J. Z.; Ma, Y.; Tang, B. Z. Hyperbranched Polytriazoles with High Molecular Compressibility: Aggregation-Induced Emission and Superamplified Explosive Detection. J. Mater. Chem. 2011, 21, 4056-4059. 
(4) Yao, B.; Mei, J.; Li, J.; Wang, J.; Wu, H.; Sun, J. Z.; Qin, A.; Tang, B. Z. Catalyst-Free Thiol-Yne Click Polymerization: A Powerful and Facile Tool for Preparation of Functional Poly(vinylene sulfide)s. Macromolecule 2014, 47, 1325-1333.

(5) Zhao, E.; Li, H.; Ling, J.; Wu, H.; Wang, J.; Zhang, S.; Lam, J. W. Y.; Sun, J. Z.; Qin, A.; Tang, B. Z. Structure-Dependent Emission of Polytriazoles. Polym. Chem. 2014, 5, 2301-2308. 